probably inappropriate. Although patients at the end of the clinic still tended to wait longer than those with earlier appointments, the new system also reduced this inequity.

Few problems were encountered in implementing the new appointments system. Such a system, however, may not be appropriate for haematology and diabeties

Effect of new appointments system on waiting times and number of patients seen, December 1988-7une 1989

\begin{tabular}{lcccc}
\hline Month & $\begin{array}{c}\text { Mean waiting time } \\
\text { (mins) }\end{array}$ & $\begin{array}{c}\text { Mean maximum waiting } \\
\text { time (mins) }\end{array}$ & $\begin{array}{c}\text { Mean No of patients } \\
\text { per clinic }\end{array}$ & $\begin{array}{c}\text { Mean total clinic } \\
\text { duration (mins) }\end{array}$ \\
\hline December 1988 & $39 \cdot 6$ & $78 \cdot 8$ & $15 \cdot 8$ & 187 \\
January 1989 & $41 \cdot 4$ & $61 \cdot 3$ & $12 \cdot 2$ & 169 \\
February 1989 & $28 \cdot 6$ & $48 \cdot 4$ & $14 \cdot 6$ & 185 \\
March 1989 & $10 \cdot 9$ & $47 \cdot 6$ & $14 \cdot 5$ & 186 \\
April 1989 & $12 \cdot 7$ & $48 \cdot 7$ & $14 \cdot 2$ & 168 \\
May 1989 & $8 \cdot 2$ & $38 \cdot 2$ & $15 \cdot 0$ & 160 \\
June 1989 & $9 \cdot 5$ & $37 \cdot 1$ & $15 \cdot 4$ & \\
\hline
\end{tabular}

clinics, when a blood test is usually required before the consultation, or if a high proportion of patients require ambulance transport.

From the economic point of view a reduction in patients' waiting time represents a cost saving. As there was no appreciable change in either the total duration of the clinics or the number of patients seen it is unlikely that the time costs had merely been transferred to the doctor. It seems reasonable to conclude that a reduction in waiting time for patients may result in improvements in efficiency.

I thank Mrs I Hall, nursing auxiliary, for her help with this study.

1 Harrison AT. Appointment systems: feasibility study of a new approach. BMf 1987;294:1465-6.

(Accepted 15 August 1990)
MRC Biostatistics Unit, Cambridge CB2 2BW Sheila $M$ Gore, PHD, senior statistician

Organ Grafting Unit, Royal Victoria Infirmary, Newcastle upon Tyne NE1 4LP

R M Ross Taylor, CHM, consultant surgeon

Thoracic Surgical Unit, Papworth Hospital, Cambridge CB3 8RE John Wallwork, FRCSED, consultant cardiothoracic surgeon

Correspondence to: Dr Gore.

BMF 1991;302: 149-53

\title{
Availability of transplantable organs from brain stem dead donors in intensive care units
}

\author{
Sheila M Gore, R M Ross Taylor, John Wallwork
}

\begin{abstract}
Objective-By audit from January to June 1989 to quantify, separately for hearts, kidneys, liver, lungs and corneas, the possible increases in transplantable organs from brain stem dead potential donors in intensive care units and to compare them with the increases achieved in October-November 1989, during intense, national publicity about transplantation.
\end{abstract}

Design-Prospective audit of all deaths in intensive care units in England from 1 January to 30 June 1989 and subsequent case study of the impact of publicity on offers and donations during OctoberNovember 1989.

Setting - 15 regional and special health authorities in England.

Patients -5803 patients dying in intensive care units, of whom 497 were confirmed as brain stem dead and had no general medical contraindication to organ donation.

Main outcome measures-Organ specific suitability for transplantation (as reported by intensive care units); consent for donation of specific suitable organs; and procurement of specific organs reported as suitable for transplantation and offered.

Results-In the $497(8.6 \%)$ brain stem dead potential donors we estimated the organ specific suitability for heart as $63 \%$, kidneys $95 \%$, liver $70 \%$, lungs $29 \%$, and corneas $91 \%$. Refusal of relatives $\mathbf{3 0 \%})$ accounted for major losses of suitable organs of all types. For kidneys the loss was equivalent to $44 \%$ of brain stem dead actual kidney donors. No discussion of organ donation was the second most important reason for missed kidney donors, the loss being equivalent to $10 \%$ of brain stem dead actual donors. Non-procurement or difficulties with allocating organs was the second most notable cause of missed suitable liver and lung donors; $29 \%(55)$ of the offered total of 189 liver donors and $27 \%$ (21) of 78 offered suitable lung donors in six months. Non-procurement of suitable, offered organs was rare for kidneys and modest, of the order of $13 \%$ and $10 \%$ respectively, for heart and corneas. Corneal donation from brain stem dead potential donors might be improved nearly as much (that is, a $78 \%$ increase in brain stem dead actual corneal donors) by specific measures to promote corneal donation when other organs are offered as by reducing the overall refusal rate. Restricted offers, non-procurement, and no discussion of donation accounted for nearly equal numbers of lost donations of hearts (each equivalent to $15 \%$ of donated hearts). During October-November 1989 when there was intense, positive publicity about transplantation the rates of refusal and non-discussion fell compared with during January-June $(22 \%, 36 / 163 v 30 \%, 138 / 460$; $7 \%, 33 / 497 v 2 \%, 4 / 167$ respectively). Offers of suitable donors increased significantly $(\mathbf{p}<0.02)$ compared with the first six months of 1989 , most notably for heart donors $(80 v 60.1$ expected) and kidney donors (122 $v 102 \cdot 1$ expected) but only for kidneys was there a noticeable $17 \%$ increase in actual donors (118 actual audited donors $v 100.8$ expected donors; $p=0.09$ ).

Conclusions-Four strategies to increase the supply of transplantable organs from brain stem dead potential donors in intensive care units were identified: $(a)$ reducing refusal of relatives $(b)$ avoiding non-procurement of actually suitable organs (by logistical initiatives) and deterioration of initially suitable organs (by donor care initiatives); (c) converting restricted offers to unrestricted offers; and (d) ensuring discussion with families. Early referral to the transplant team or coordinator gives time for discussion about donor care and agreement on medical suitability for donation of specific organs. Solving some of the logistical problems of nonprocurement may be a prerequisite for increased offers to be translated into increased donations. The impact of publicity therefore needs to be measured on offers of suitable donors as well as by actual donations.

\section{Introduction}

Confidential audit of all deaths in intensive care units in England (except coronary care only units and neonatal intensive care units) was initiated by the Department of Health after a recommendation by the Working Party on the Supply of Donor Organs for Transplantation.' It gave estimates of 1700 possible brain stem deaths and 1200 confirmed brain 
stem deaths annually in England, ${ }^{2}$ which are half and one third respectively of Jennett's much quoted figure published in $1981 .{ }^{3}$ Also reported was a $30 \%$ ( $95 \%$ confidence interval $24 \%$ to $36 \%$ ) rate of refusal of donation by relatives; in only $6 \%(3 \%$ to $9 \%)$ of cases was organ donation not discussed with the family of a brain stem dead potential donor.

In this second audit report we quantify for heart, kidneys, liver, lungs, and corneas the possible increases in transplantable organs from brain stem

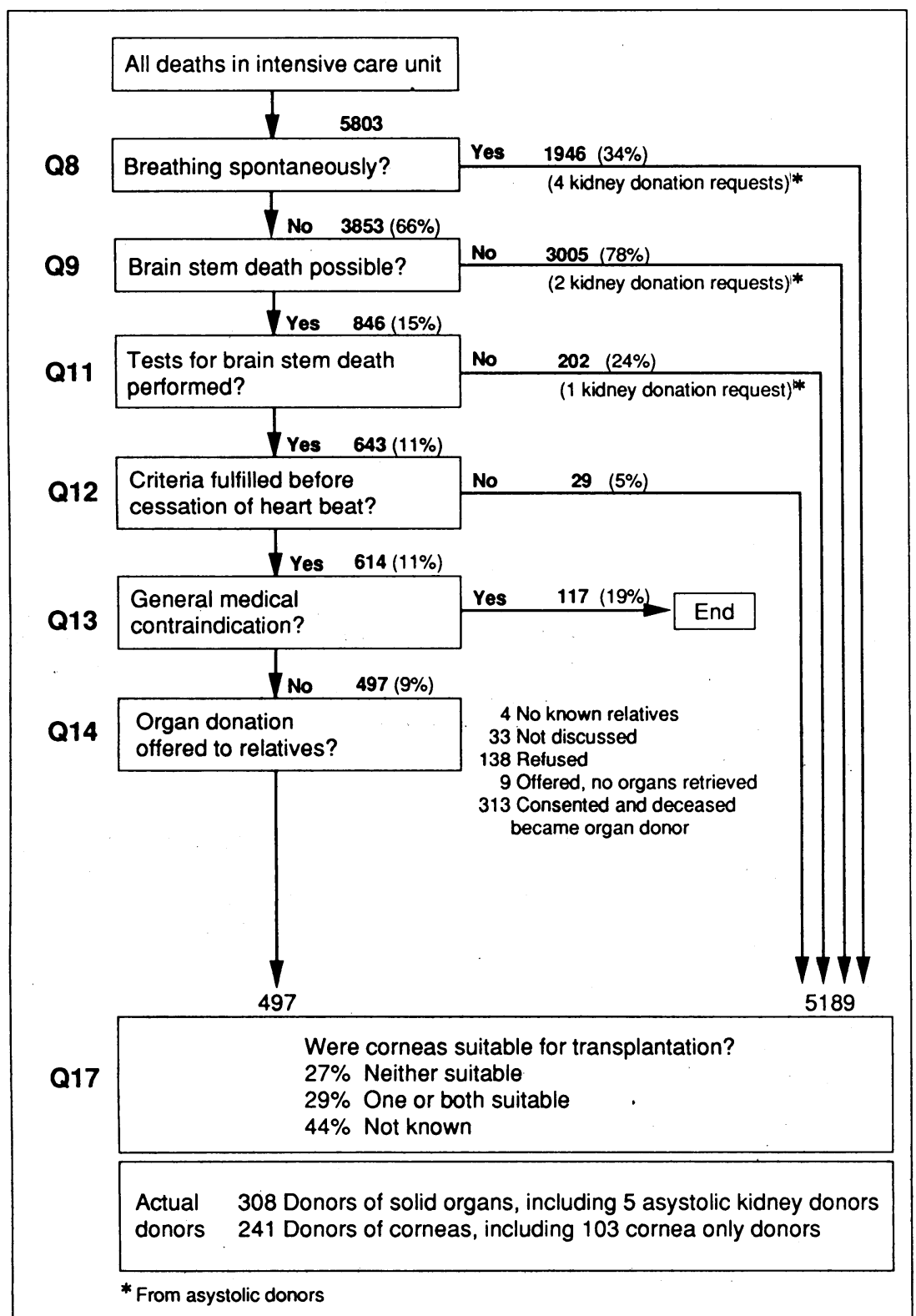

Phases 1 and 2 of audit of brain stem dead transplantation donors, Fanuary-Fune 1989

TABLE I - Suitability of hearts from potential donors with brain stem death for transplantation as reported by intensive care units. Figures are numbers of donors

\begin{tabular}{lccccccc}
\hline & \multicolumn{3}{c}{ Suitable hearts } & & \\
\cline { 2 - 5 } & Donated & $\begin{array}{c}\text { Not } \\
\text { procured }\end{array}$ & $\begin{array}{c}\text { Not } \\
\text { offered }\end{array}$ & $\begin{array}{c}\text { Unsuitable } \\
\text { hearts }\end{array}$ & $\begin{array}{c}\text { Other } \\
\text { hearts }\end{array}$ & Total \\
\hline $\begin{array}{l}\text { No known relatives or } \\
\text { transplantation not discussed }\end{array}$ & 1 & & 12 & 19 & 5 & 37 \\
$\begin{array}{l}\text { Refusal by relatives } \\
\text { Consent }\end{array}$ & 155 & 23 & 15 & 111 & 22 & 138 \\
\hline Total & 156 & 23 & 114 & 159 & 45 & 497 \\
\hline
\end{tabular}

Given relatives' consent and organ suitability for transplantation was determined as:

$\%$ Suitable $=\frac{193}{(193+111)} \times 100 \%=63 \%(95 \%$ confidence interval $58 \%$ to $69 \%)$.

$\star$ Includes suitability not known or donation not known, or both.

tncluding 36 discussed with transplant team or coordinator.

Including 13 for whom there was no offer. dead potential donors, which are estimable with data from the first and second phases (1 January 1989 to 30 June 1989) of the confidential audit of all deaths in intensive care units in England. Quantification depends on three variables: organ specific suitability for transplantation (as reported by intensive care units), consent for donation of specific suitable organs; and procurement of specific organs that are reported as suitable for transplantation and have been offered.

\section{Methods}

The audit started on 1 January 1989 in regional and special health authorities in England and was coordinated through designated regional staff as previously described. ${ }^{2}$ For patients with confirmed brain stem death and no general medical contraindication to organ donation the audit recorded whether organ donation was suggested to the relatives, which solid organs were suitable for transplantation and which were donated; and whether corneas were suitable for transplantation and were donated.

Data on the suitability of organs for transplantation were reported by the staff of the intensive care unit without necessary corroboration by a transplant team and possibly without consideration of deterioration in suitability between confirmation of brain stem death and arrival of the transplant team. These caveats on reported suitability of organs are important, especially for lungs.

\section{Results}

The figure shows the audit flow chart for 5803 $(93.3 \%)$ deaths in intensive care units reported from 1 January 1989 to 30 June 1989 . In 497 patients $(8.6$ (SE $0.4 \%)$ ) brain stem death was confirmed in the absence of any general medical contraindication to organ donation, and this analysis is confined to these 497 potential donors. In four patients there were no known relatives and in 33 there was no discussion of organ donation; organ donation was suggested to relatives of 460 patients and the refusal rate was $30 \%$ (138 refusals) (95\% confidence interval $26 \%$ to $34 \%$ ). Not all organs from these lost potential donors were suitable for transplantation, as shown for hearts (table I) and for other organs (appendix, p 152).

SUITABILITY OF HEARTS FOR TRANSPLANTATION

Table I shows the suitability of hearts for transplantation against the background of relatives' consent to organ donation and also whether "suitable" hearts were donated. Suitability was not always ascertained; ascertainment was more likely if the relatives consented to organ donation than otherwise $(94 \%$ (304/322) cases of consent $v 85 \%(148 / 175)$ ). Moreover, the transplant team or coordinator was almost always contacted if the relatives consented to organ donation (313/322, 97\% of donors), but less often with refusals $(57 / 138,41 \%)$ and when there were no known relatives or organ donation was not discussed $(5 / 37,14 \%)$.

Reliability of the judgment of suitability of the heart as well as its ascertainment was therefore superior in cases of consent, and likewise for other organs (appendix). We therefore based our estimates of organ specific suitability on the subset of 322 cases of consent for which suitability was ascertained. Among 304 donors with consenting relatives, for whom suitability of the heart for transplantation was ascertained, the heart was reported as suitable in 193 -that is, in $63 \%$ $(58 \%$ to $69 \%)$.

SUITABILITY OF OTHER ORGANS FOR TRANSPLANTATION

With the above method we estimated that in brain stem dead potential donors the kidneys were suitable 
for transplantation in $95 \%$ (92\% to $97 \%$ ); the liver in $70 \%(64 \%$ to $75 \%)$; and the corneas in $91 \%(87 \%$ to $94 \%)$. The corresponding estimate of $45 \%$ for lungs does not fit with experience of cardiothoracic surgeons. Indeed, among the 55 donors with lungs reported as suitable but not procured (appendix), non-suitability of the lungs at donor operation may be inferred for the 34 patients who became heart donors. In the other 21 patients we did not know whether a cardiothoracic team attended; the heart was either not suitable (two), not offered (one), or "suitable but not procured" (18) Inferring non-suitability of lungs at donor operation in 34 of the 55 donors revises to $29 \%$ ( $24 \%$ to $34 \%$ ) our estimate of brain stem dead potential donors whose lungs are probably still suitable for transplantation at the time of donor operation.

\section{POSSIBLE INCREASES FOR HEART DONATION}

From January to June 1989,156 heart donors were reported to the confidential audit. Table II shows that an additional 155 suitable heart donations would have been possible if there were no refusal by relatives (a); no non-procurement (b); no restricted permission or offers (c); and no non-discussions (d). These possible increases are derived from table I as follows. Among the 138 potential donors whose relatives refused organ donation, we estimated that 87 potential donors $(63 \%)$ had suitable hearts (a); 23 suitable hearts were not procured (b). Restricted permission by otherwise consenting relatives led to no offer of a suitable heart in 15 donors and in 13 other potential donors the heart was not offered, its suitability for transplantation being reported as "not known" (footnote to table I). Yet of the 13 potential donors we expect the heart to have been suitable in eight $(63 \%)$. Table II therefore shows the loss of 23 suitable hearts $(15+8)$ because of no offer by otherwise consenting relatives (c). Of the 37 potential donors who had no known relatives or for whom organ donation was not suggested to the family, we estimate that $23(63 \%)$ had suitable hearts from whom there was only one donation (see table I) and so we estimate the loss of 22 suitable hearts due to nondiscussion $(\mathrm{d})$

TABLE II - Possible increases in transplantable organs from brain stem dead potential donors as reported by intensive care units, January-fune 1989

\begin{tabular}{|c|c|c|c|c|c|c|}
\hline & Heart & Kidney & & Liver & Lung & Cornea \\
\hline Number of transplanted donors from audit & 156 & 300 & 1 & 134 & 57 & 151 \\
\hline Possible increase in donors of suitable organs & 155 & 171 & & 206 & 82 & 290 \\
\hline No refusal by relatives (a) & 87 & 131 & 97 & & 40 & 125 \\
\hline No non-procurement $(b)$ & 23 & 4 & 55 & & 21 & 16 \\
\hline No restricted permissions or offers $(c)$ & 23 & 4 & 29 & & 11 & 118 \\
\hline No non-discussion $(\mathrm{d})$ & 22 & 32 & 25 & & 10 & 31 \\
\hline $\begin{array}{l}\% \text { Possible increase through measures to } \\
\text { improve rates of consent }(a+c+d)\end{array}$ & 85 & 98 & & 73 & 74 & 94 \\
\hline
\end{tabular}

${ }^{\star}$ Revised to take some account of deterioration in lungs by time of donor operation.

TABLE III-Case study of offered and actual donors Fanuary-Fune and October-November 1989. Figures are numbers except when stated otherwise

\begin{tabular}{|c|c|c|c|c|c|}
\hline Audit phase & Heart & Kidney & Liver & Lung ${ }^{\star}$ & Cornea \\
\hline \multicolumn{6}{|c|}{ Audit offers compared with expected offers } \\
\hline "Suitable" offered donors: & & & & & \\
\hline Jan-Jun & 179 & 304 & 189 & 78 & 167 \\
\hline Oct-Nov & 80 & 122 & 73 & 32 & 61 \\
\hline \multicolumn{6}{|l|}{ Expected offers Oct-Nov (if no change from } \\
\hline Jan to Jun) & $60 \cdot 1$ & $102 \cdot 1$ & $63 \cdot 5$ & $26 \cdot 2$ & $56 \cdot 1$ \\
\hline \multicolumn{6}{|c|}{ Audit donors compared with expected donors } \\
\hline Actual donors: & & & & & \\
\hline Jan-Jun & 156 & 300 & 134 & 57 & 151 \\
\hline Oct-Nov & 55 & 118 & 48 & 16 & 53 \\
\hline Expected donors Oct-Nov (if no change from & 52 & $100-8$ & 150 & 10.? & 50.7 \\
\hline \multicolumn{6}{|c|}{ Non-procurement $(\% \dagger)$} \\
\hline Jan-Jun & 13 & 1 & 29 & 27 & 10 \\
\hline Oct-Nov & 19 & 3 & 34 & 50 & 13 \\
\hline
\end{tabular}

Revised to take some account of deterioration in lungs by time of donor operation.

†Defined as "suitable" but not procured/("suitable" but not procured plus suitable and donated) $\times 100 \%$.
POSSIBLE INCREASES FOR DONATION OF OTHER ORGANS

Possible increases in donors of other organs (table II) were worked out similarly using the tables in the appendix and the above organ specific estimates of suitability for transplantation.

Table II shows that for every organ measures to improve the rates of consent $(a+c+d)$ have greater potential than initiatives in procuring or allocating organs to increase the supply of transplantable organs from brain stem dead potential donors. The major gain derives from measures to reduce the overall refusal rate (a) but corneal donation might be improved as much by specific measures to promote corneal donation when other organs are offered. Failure to discuss organ donation with relatives (d) comes second after refusal by relatives in accounting for the loss of suitable kidney donors whereas difficulties in procuring or allocating organs are the second most notable cause of missed suitable liver and reportedly suitable lung donors. Non-procurement, restricted offers, and no discussion $(b+c+d)$ accounted for nearly equal numbers of lost heart donations.

Non-procurement of organs that were reportedly suitable for transplantation and were offered accounted for 23 hearts $(13 \%$ of the offered total of $179 ; 95 \%$ confidence interval $8 \%$ to $18 \%$ ); only four kidney donors (1\% of 304 offered kidney donors); 55 livers ( $29 \%$ of the offered total of $189 ; 22 \%$ to $36 \%$ ); 21 lung donors $(27 \%$ of 78 offered lung donors potentially still suitable at donor operation; $17 \%$ to $37 \%$ ); and 16 corneal donors ( $10 \%$ of 167 offered corneal donors; $5 \%$ to $14 \%$ ). Thus non-procurement of suitable offered organs was rare for kidneys; modest, of the order of $13 \%$ and $10 \%$, for heart and corneas respectively; and substantial, at around $30 \%$, for liver and lungs.

\section{CASE STUDY OF OFFERS AND DONATIONS DURING} PUBLICITY CAMPAIGN

Even if effective publicity and professional education (affecting measures $a$ and $c$ and $d$ ) lead to increased offers of suitable organs, non-procurement could compromise actual donations. This will happen if non-procurement occurs owing to saturation of existing transplant services so that extra offers cannot be utilised rather than because of different criteria of suitability being applied by intensive care doctors and transplant doctors.

During October-November 1989 there was intense, sustained publicity about transplantation, the original focus of which was two patients who desperately needed liver transplants. We reviewed its impact on refusal by relatives and failure to ask about organ donation and on suitable offered donors and actual donations.

Compared with the $30 \%$ refusal rate in January-June 1989 that during October-November was 22\% (36 out of 163 families; $p=0.06$ ); the rate of non-discussion was $7 \%$ in January-June, and only $2 \%$ (four out of 167 families) in October-November. Restricted offers of suitable hearts, however, were little changed (15/193 $(8 \%)$ in January-June $v 5 / 75(7 \%)$ in October-November), those of suitable livers were 16 out of $204(8 \%)$ in January-June compared with four out of $77(5 \%)$ in October-November. If families who make restricted offers do so after due consideration they may be unlikely to change their decision, irrespective of publicity.

Table III shows suitable offered donors in two audit periods: January-June 1989 (out of 497 brain stem dead potential donors) versus October-November 1989 (out of 167 potential donors). For comparison are shown the expected offers for October-November if there was no change in offer pattern from January-June. Increased offers of suitable donors occurred in OctoberNovember compared with the first six months of 1989 $\left(\chi_{5}^{2}=13 \cdot 6, p=0 \cdot 02\right)$, most notably for offered heart and 
kidney donors. Table III also shows actual donors in the January-June audit and in that of OctoberNovember. For comparison are shown the numbers of donors expected for October-November if there was no change in donor pattern, including non-procurement rates, from January-June. We note that only for kidney donors in October-November was there a noticeable $17 \%$ increase in donors compared with January-June

\section{Appendix}

Suitability for transplantation of organs from brain stem dead potential donors alone as reported by intensive care units. Figures are numbers of donors

\begin{tabular}{|c|c|c|c|c|c|c|}
\hline & \multicolumn{3}{|c|}{ Suitable corneas } & \multirow[b]{2}{*}{$\begin{array}{c}\text { Unsuitable } \\
\text { corneas }\end{array}$} & \multirow[b]{2}{*}{ Other ${ }^{\star}$} & \multirow[b]{2}{*}{ Tota } \\
\hline & Donated & $\begin{array}{c}\text { Not } \\
\text { procured }\end{array}$ & $\begin{array}{c}\text { Not } \\
\text { offered }\end{array}$ & & & \\
\hline $\begin{array}{l}\text { No known relatives or } \\
\text { transplantation not discussed } \\
\text { Refusal by relatives } \\
\text { Consent }\end{array}$ & $\begin{array}{r}3 \\
148\end{array}$ & 16 & $\begin{array}{c}16 \\
104 \dagger \\
87\end{array}$ & $\begin{array}{r}5 \\
7 \\
26\end{array}$ & $\begin{array}{l}13 \\
27 \\
45 \ddagger\end{array}$ & $\begin{array}{r}37 \\
138 \\
322\end{array}$ \\
\hline Total & 151 & 16 & 207 & 38 & 85 & 497 \\
\hline
\end{tabular}

Given relatives' consent and organ suitability for transplantation was determined as:

$\%$ Suitable $=\frac{251}{(251+26)} \times 100 \%=91 \%(95 \%$ confidence interval $87 \%$ to $94 \%)$.

^Includes suitability of corneas not known or donation not known, or both. tIncluding 45 discussed with transplant team or coordinator.

Including 34 for whom there was no offer.

\begin{tabular}{lccccccr}
\hline & \multicolumn{5}{c}{ Suitable kidney pair } & & \\
\cline { 2 - 6 } & Donated & $\begin{array}{c}\text { Not } \\
\text { procured }\end{array}$ & $\begin{array}{c}\text { Not } \\
\text { offered }\end{array}$ & $\begin{array}{c}\text { Unsuitable } \\
\text { kidney pair }\end{array}$ & Other & Total \\
\hline $\begin{array}{l}\text { No known relatives or } \\
\text { transplantation not discussed }\end{array}$ & 3 & & 15 & 12 & 7 & 37 \\
$\begin{array}{l}\text { Refusal by relatives } \\
\text { Consent }\end{array}$ & 297 & 4 & $116 \dagger$ & 2 & 17 & 15 & 138 \\
\hline Total & 300 & 4 & 133 & 36 & 24 & 497 \\
\hline
\end{tabular}

Given relatives' consent and organ suitability for transplantation was determined as:

$\%$ Suitable $=\frac{303}{(303+17)} \times 100 \%=95 \%(92 \%$ to $97 \%)$.

^Includes suitability not known or donation not known, or both.

tIncluding 51 discussed with transplant team or coordinator.

fIncluding two for whom there was no offer.

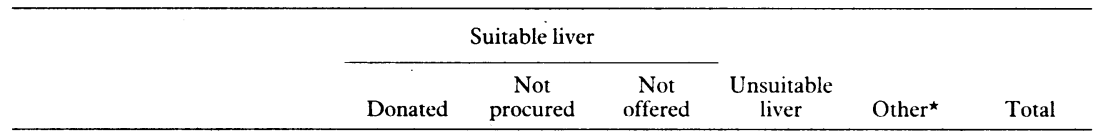

\begin{tabular}{|c|c|c|c|c|c|c|}
\hline $\begin{array}{l}\text { No known relatives or } \\
\text { transplantation not discussed } \\
\text { Refusal by relatives } \\
\text { Consent }\end{array}$ & 133 & 55 & $\begin{array}{l}14 \\
93 \dagger \\
16\end{array}$ & $\begin{array}{l}15 \\
20 \\
88\end{array}$ & $\begin{array}{c}7 \\
25 \\
30 \ddagger\end{array}$ & $\begin{array}{r}37 \\
138 \\
322\end{array}$ \\
\hline Total & 134 & 55 & 123 & 123 & 62 & 497 \\
\hline
\end{tabular}

Given relatives' consent and organ suitability for transplantation was determined as:

$\%$ Suitable $=\frac{204}{(204+88)} \times 100 \%=70 \%(64 \%$ to $75 \%)$.

*Includes suitability not known or donation not known, or both.

tIncluding 38 discussed with transplant team or coordinator.

$\neq$ Including 18 for whom there was no offer.

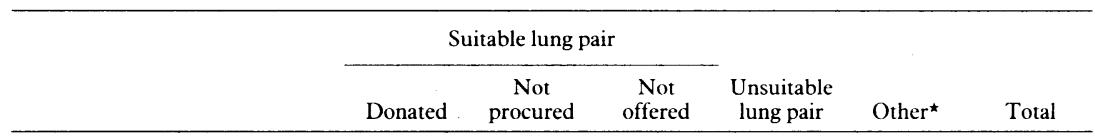

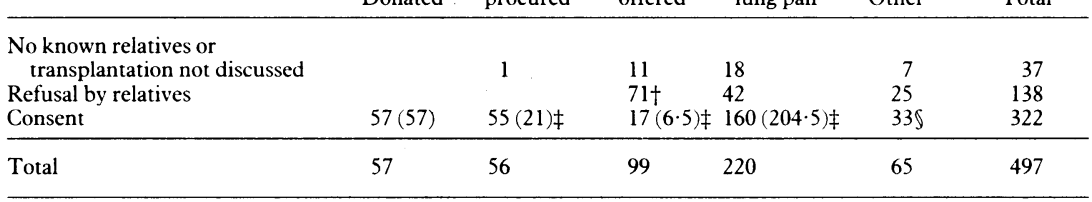

Given relatives' consent and organ suitability for transplantation was determined as:

$\%$ Suitable $=\frac{129}{(129+160)} \times 100 \%=45 \%(39 \%$ to $50 \%)$.

*Includes suitability not known or donation not known, or both

†Including 28 discussed with transplant team or coordinator.

$\ddagger$ Revised estimate (see text) taking some account of deterioration in lungs by time of donor operation in a minimum of 34 out of 55 donors.

$\%$ Suitable $=\frac{57+21+\frac{21}{55} \times 17}{289} \times 100 \%=29 \%(24 \%$ to $34 \%)$.

$\S$ Including 16 for whom there was no offer. $(p=0 \cdot 09)$. The global comparison $\left(\chi_{5}^{2}=3 \cdot 90\right)$ of actual and expected donors based on January-June is unexceptional. Thus extra offers of suitable hearts, livers, lungs, and corneas in October-November $\left(\chi_{4}^{2}=9 \cdot 7\right.$, $\mathrm{p}<0 \cdot 05)$ were not translated into donations. However, non-procurement rates (table III) increased in OctoberNovember compared with January-June, which may explain why increases in actual donations (kidneys excepted) were not observed.

\section{Discussion}

Confidential audit of all deaths in intensive care units (1 January-30 June 1989) confirmed a 30\% rate of refusal by relatives, which is comparable with the British Kidney Patient Association's annual survey conducted by Gallup in March 1989, in which $70 \%$ of 1003 people surveyed said that they would be willing to donate their kidneys after death. If an organ is not suitable for transplantation it will not be used, consent notwithstanding. Thus refusal by relatives or no discussion about organ donation when organs are unsuitable anyway does not decrease the supply of transplantable tissue. We estimated organ specific suitability in brain stem dead potential donors from intensive care units for heart as $63 \%$; kidneys $95 \%$; liver $70 \%$; lungs $29 \%$; and corneas $91 \%$.

Refusal by relatives accounts for major losses of suitable organs. Notably, these include 131 lost kidney donors in six months, equivalent to $44 \%$ of brain stem dead actual kidney donors. No discussion of organ donation was the second reason for missed kidney donors, with 32 kidney donors lost on this account, equivalent to $10 \%$ of brain stem dead actual kidney donors from intensive care units.

Restricted permission (or no offer) by relatives who consented to other organ donation meant the loss of four suitable kidney donors, equivalent to $1 \%$ of brain stem dead actual kidney donors, but the loss of 118 suitable corneal donors, equivalent to $78 \%$ of actual corneal donors. Measures to promote corneal donation when relatives consent to donation of solid organs could increase substantially the supply of HLA typed corneal tissue and so improve the degree of HLA matching available to patients who need it, about one quarter in the corneal transplantation waiting list. ${ }^{4}$ Restricted permission (or no offer) accounted for the loss of 23 hearts, 29 livers, and 11 suitable lung donors, equivalent to $15 \%, 22 \%$, and $19 \%$ respectively of corresponding actual donors. Oversight by medical or nursing staff - in not reminding relatives that offers of suitable heart, liver, lungs or corneas give life or sight - could masquerade as relatives' unwillingness and so be counted inappropriately as restricted permission. We recommend that donation of other organs besides kidneys should be discussed routinely when organ donation is suggested to relatives.

Non-procurement of suitable organs which had been offered for transplantation was rare for kidneys ( $1 \%$ of 304 brain stem dead offered kidney donors); modest for hearts and corneas $(13 \%$ and $10 \%$ of offered donors of hearts and corneas, 23 heart and 16 corneal donors respectively not procured); but substantial for. liver and lungs at around $30 \%$ of offered livers and reportedly suitable lungs ( 55 livers and 21 lung donors not procured in six months).

Possible reasons for non-procurement of offered, reportedly suitable heart, liver, or lungs are different criteria of suitability being applied by intensive care and transplant doctors; deterioration in condition of the donor so that organs thought suitable at the time of offer were not so when the transplant team arriveds; non-availability of the retrieval surgical or anaesthetist team or of the recipient (because choice depends on physical size); insufficient cooperation amongst 
retrieval surgeons resulting in non-procurement of some organs ${ }^{6}$; non-availability of theatre time, of staffed intensive care bed (for several days postoperatively), or of sufficient units of appropriate blood (for liver transplantation).

Publicity has been recognised as a key to the future of organ donation, but finding solutions to some of the problems of non-procurement, as well as avoiding deterioration of donor organs, ${ }^{8}$ may be prerequisites for increased offers to be translated into increased donations. During October-November 1989 sustained, national publicity about transplantation was associated with reduction by a quarter in refusal by relatives (from $30 \%$ to $22 \%$ ) and a reduction in failure to ask about organ donation of about two thirds. Compared with the first six months of 1989, October-November saw appreciable increases (around a fifth) in suitable offered donors of specific organs, but only in the case of kidneys was there a corresponding $17 \%$ increase in actual donations; increased rates of non-procurement were also a feature. If transplant services are already operating to capacity full advantage cannot be taken of increased offers of such organs as liver, heart, or lungs. Percentage increase in actual donations then underestimates the impact of publicity and other measures to enhance offers of suitable organs for transplantation. A side effect of the October-November publicity to enhance offers might have been some relaxing of criteria of reporting or assessing organ suitability by intensive care units, which had to be compensated for by increased rates of non-procurement of reportedly, but not actually, suitable organs.
Confidential audit of all deaths in intensive care units is supported by a grant from the Department of Health. Views expressed in the paper are those of the authors alone, however, and should not be ascribed to the Department of Health. We thank data managers Miss Deborah Cable and Mrs Annabel Holland for their careful work, and our regional liaison officers Dr Julie Bagnall, Sister Deirdre Barr, Mr A J Cassidy, Mr J Chapman, Mr R Collins, Miss Nilli Lamakan, Mrs Christine Lyon, Miss Jenny Wright, Mr Alan Waller, Miss F Martin, Mr M O'Donnell, Dr M R Owen, Dr John Raison, Dr D Richardson, Dr M Rivlin, Dr T Sussman, $\mathrm{Mr}$ Frank Stockwell, and Ms Carol Hall for their contacts with intensive care units.

Mr Myc Riggulsford, public relations officer at the United Kingdom Transplant Service, gave constructive advice on audit form content. Also consulted were the British Transplantation Society, British Organ Donor Society, Faculty of Anaesthetists, Intensive Care Society, Joint Consultants Committee, Regional and District General Managers, Royal College of Physicians, Society of British Neurological Surgeons, and United Kingdom Transplant Service Management Committee.

1 Working Party on the Supply of Donor Organs for Transplantation. Repor London: HMSO, 1987. (Chairman: Sir Raymond Hoffenberg.)

2 Gore SM, Hinds CJ, Rutherford AJ. Organ donation from intensive care units in England. BMF 1989;299:1193-7.

3 Jennett B. Brain death. Br F Anaesth 1981;53:1111-9.

4 UK Transplant Service. Annual report 1989. UK Transplant Service: Bristol, 1989.

Grebenck CR, Hinds CJ. Management of the multiple organ donor. Br f Hosp Med 1987: Jul: 62-5.

Wallwork J. Organs for transplantation. BMf 1989;299:1291.

7 Kemp G, Alderson A, Towers M. Transplant crisis "kills one in five." Sunday Express 1989 Aug $27: 1$ wers $M$. Tra

8 Odom NJ. Organ donation 1-Management of the multiorgan donor. $B M \mathcal{Y}$ 1990;300:1571-3.

(Accepted 16 November 1990)
Health Care Evaluation Unit, Department of Epidemiology and Public Health Medicine, University of Bristol, Canynge Hall, Bristo BS8 2PR

Clive Richards, FRCGP, regional adviser in general practice audit, South Western Regional Health Authority

BMF 1991;302:153-5

\title{
Audit in Person
}

\section{Impact of medical audit advisory groups}

\author{
Clive Richards
}

Medical audit is a key feature of recent changes to the NHS and is an essential part of the new contract for general practice. Although the term medical audit is used freely, it is necessary to define it. Many definitions have been attempted, but all have in common a systematic critical analysis of aspects of quality of care, reference to standards of care, and commitment to change. Medical audit is not a synonym for traditional review or research activities, as emphasised recently in the report The Quality of Medical Care' by the government's standing medical advisory committee in its robust statement that "the essential nature of medical audit is a frank discussion between doctors, on a regular basis and without fear of criticisn, of the quality of care provided as judged against agreed standards but in a context which allows evolutionary change in such standards."

Medical audit for family doctors is complicated by additional audits of their contractual obligations - for example, measurement of procedures for payment. Audit activities must differentiate between contractual audit, which is a management task whose prime purpose is control, and medical audit, which is a professional task with a prime purpose of education. The dividing line between these two types of audit is often blurred, and the skills and resources for each can be shared. Often the crucial difference between the two will be that of intention. An audit of prescribing to exert downward pressure on costs is clearly a contractual audit and a managerial activity whereas the same procedure undertaken voluntarily to develop a logical treatment policy is a medical audit and an educational activity. Any organised medical audit activity in general practice must acknowledge this distinction.

\section{Structure}

The formal mechanism for organising medical audit in general practice will be via a new committee, the medical audit advisory group, structural arrangements for which were described in Medical Audit in the Family Practitioner Services health circular (HC (FP)(90) 8). The group will be a committee of the family health services authority, which will appoint its members. There will be up to 12 medically qualified members, most of whom will be general practitioner principals appointed after consultation to ensure that they command the confidence of the profession locally. Appointment to the group will take into account factors such as the distribution of urban and rural practices and the sex and ethnic composition of the local general practitioners. In addition, the group will contain doctors with recognised skill and experience of medical audit. The circular also suggests appointment of a local consultant associated with audit activities in the hospital services and a public health physician. The group will also need to liaise with those responsible for postgraduate medical education, and so the general practitioner members will need to include representatives of the important local and regional educational organisations. 